\title{
Infantile Hemangioma Presenting as Colocolic Intussusception in an Infant Case Report with Review of Pathologic Lead Points
}

\author{
Rehan Rais (D), Iván González (iD), Jacqueline M. Saito, and Louis P. Dehner \\ From the Lauren V. Ackerman Laboratory of Surgical Pathology, and Division of Pediatric Surgery, St. Louis Children's Hospital, \\ Washington University Medical Center, St. Louis, MO, USA
}

Correspondence should be addressed to Rehan Rais; rrais@wustl.edu

Received 29 March 2018; Accepted 10 June 2018; Published 24 June 2018

Academic Editor: Amalia Schiavetti

Copyright $(92018$ Rehan Rais et al. This is an open access article distributed under the Creative Commons Attribution License, which permits unrestricted use, distribution, and reproduction in any medium, provided the original work is properly cited.

\begin{abstract}
Infantile hemangioma ( $\mathrm{IH}$ ) is one of the most common vascular anomalies of early childhood and is usually recognized in the first few weeks to months of life as a solitary cutaneous lesion. This report documents our experience with a GLUT-1 positive IH presenting as the pathologic lead point in a colocolic intussusception in a 10-week-old infant who had no skin lesions. Literature suggests approximately $2 \%$ of all children presenting with an intussusception require surgical intervention; however, an IH as the pathologic lead point is unique.
\end{abstract}

\section{Introduction}

The concurrence of intussusception and infantile hemangioma $(\mathrm{IH})$ should not be entirely surprising, since the former is one of the most common causes of bowel obstruction, and the latter is the commonest cutaneous soft tissue tumor and vascular anomaly in infancy [1-4]. However, as our case illustrates, IH of the colon was the cause of a colocolic intussusception in a 10-week-old female infant which would appear to be an extraordinary coincidence in our review of the literature.

Intussusception is a well-known clinical entity to the pediatric surgeon as a cause of intestinal obstruction in children less than 5 -years-old at presentation $[1,5]$. In most children ( $90 \%$ or greater), the intussusception is an ileocolic invagination of the ileum into the cecum ( $85 \%-90 \%$ of cases) and is idiopathic in the absence of a pathologic lead point (in greater than $90 \%$ of cases) $[1,5,6]$. Most cases are managed without need for surgical resection $[1,2]$.

Infantile hemangioma as a cutaneous and/or subcutaneous lesion has a prevalence rate of $4.5 \%$ in infants at the age of 9 to 12 months $[3,4]$. The incidence has increased over the past 30 years and has been associated with preterm birth and pregnancy complications [7, 8]. Visceral involvement, usually in the presence of five or more cutaneous IHs or diffuse infantile hemangiomatosis, is both rare and accompanied by multifocal or diffuse hemangiomatosis of the liver or in extraintestinal mucous membranes [9-11].

This report documents our experience with a localized $\mathrm{IH}$ of the colon. One earlier case in the literature is similar to ours, but the nature of the "capillary hemangioma" was not further characterized since immunohistochemistry for GLUT-1 was not performed $[12,13]$.

\section{Case Report}

2.1. Clinical Summary. A 10-week-old girl was the product of a full-term pregnancy which was complicated by maternal hypertension. No significant past medical or family history was present. The patient presented with a one day history of multiple episodes of nonbilious emesis, hematochezia, lethargy, and fussiness. On physical examination, the abdomen was diffusely tender to palpation with mild distension, and bowel sounds were audible. No cutaneous vascular lesions were noted at the time.

An abdominal ultrasound showed an apparent colocolic intussusception with no substantial interloop fluid collection, and color Doppler flow was demonstrated within 


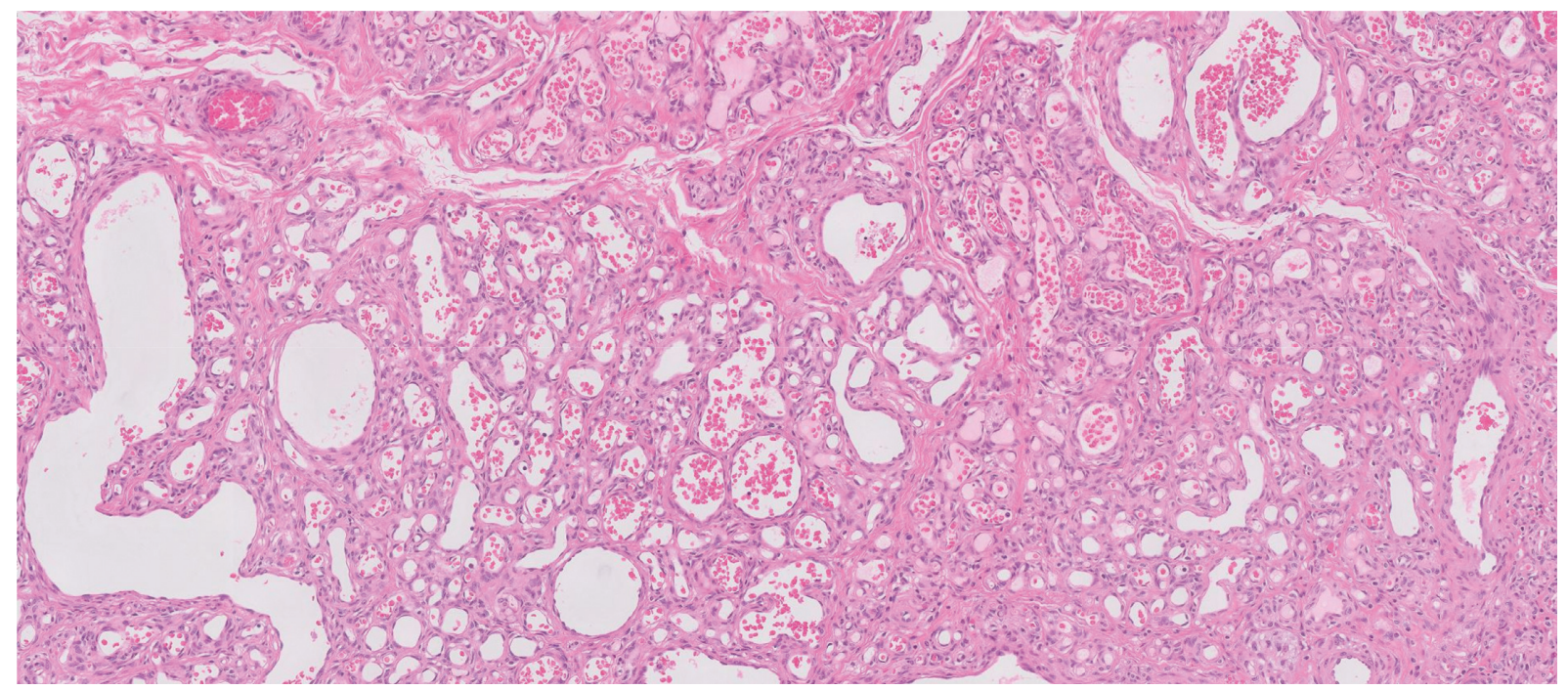

(a)

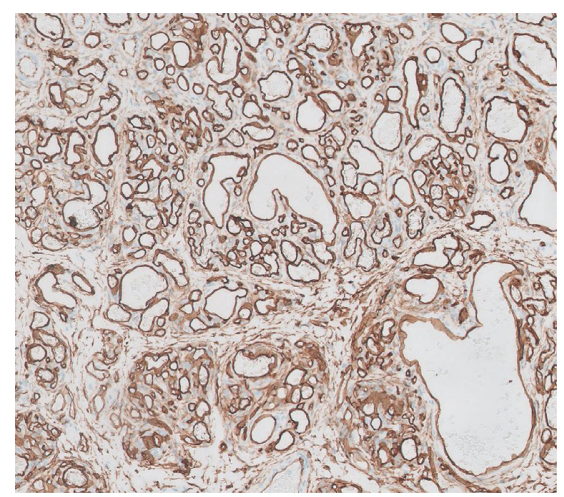

(b)

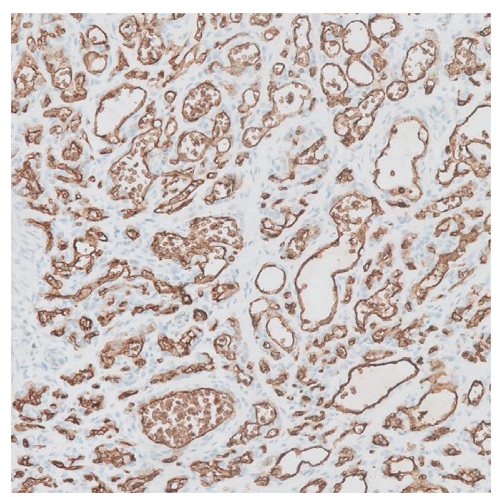

(c)

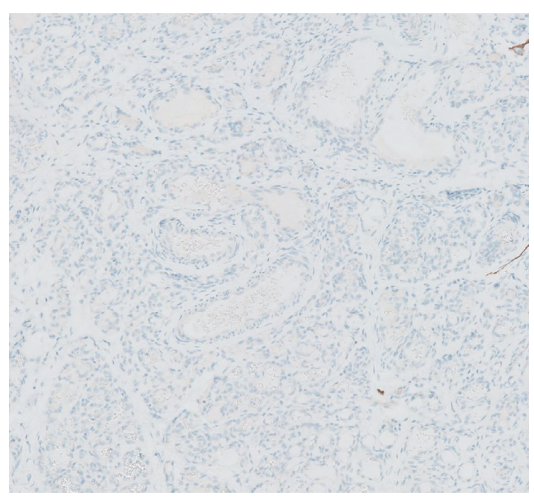

(d)

FIGURE 1: Histological sections showing lamina propria involved by a dense network of capillary-sized vascular spaces (a); immunohistochemistry was performed which shows endothelial positivity for, CD31 (b), GLUT-1 (c), and nonreactivity for D2-40 (d).

TABle 1: Pathologic lead points in intussusceptions. Review of five series.

\begin{tabular}{|c|c|c|c|c|c|c|}
\hline & Banapour (15) & Rubinstein (16) & Ong (17) & $\operatorname{Lin}(6)$ & Wong (18) & $n(\%)$ \\
\hline Meckel's diverticulum & 7 & 2 & 27 & 32 & 8 & $76(46)$ \\
\hline Polyps, NOS & - & - & 9 & 5 & 7 & $21(13)$ \\
\hline Duplication cyst & - & - & 4 & 14 & 2 & $20(12)$ \\
\hline Lymphoma & - & - & 5 & 4 & 1 & $10(6)$ \\
\hline Multiple polyps & - & 3 (PJS) & 3 (PJS, FAP) & 3 (PJS) & - & $9(5)$ \\
\hline Lymphoid hyperplasia & 4 & - & - & - & - & $4(2)$ \\
\hline Vascular lesion & 1 & - & - & 2 (hematoma) & - & $3(2)$ \\
\hline Neuroendocrine tumor & - & - & 2 & - & - & $2(1)$ \\
\hline Metastatic tumor & 1 (EWS) & $1(\mathrm{WT})$ & - & - & - & $2(1)$ \\
\hline Other & 1 & 2 (HSP) & 6 & 5 & 3 & $17(10)$ \\
\hline Total PLPs & $14(9 \%)$ & $8(6 \%)$ & $56(7 \%)$ & $65(7 \%)$ & $21(0.4 \%)$ & $164(2 \%)$ \\
\hline Total cases & 153 & 141 & 802 & 986 & 5,096 & 7,025 \\
\hline
\end{tabular}

PJS = Peutz-Jeghers syndrome; FAP = familial adenomatous polyposis; EWS = Ewing sarcoma; WT = Wilms tumor; HSP = Henoch-Schönlein purpura; $\mathrm{PLP}=$ pathologic lead point.

the walls of the intussuscipiens and intussusceptum. A reduction of the intussusception was attempted with air contrast enema, and the intussusception was initially present at the rectosigmoid junction. With pressure maintained at less than $120 \mathrm{~mm} \cdot \mathrm{Hg}$, the intussusception was reduced to the proximal descending colon, but the patient developed free intraperitoneal air apparent by fluoroscopy. During laparoscopic exploration, an intussusception was identified at the level of the distal descending colon, and fibrinous exudate was found along the descending colon, consistent with a perforation site. A segmental colonic resection with anastomosis was performed. 
2.2. Pathologic Findings. The resected segment of large intestine showed a telescoped segment of intestine. The intestinal wall measured from 0.2 to $0.5 \mathrm{~cm}$. A minute gross perforation was identified; however, there was no evidence of a gross vascular malformation. Microscopic examination showed mucosal ischemic changes with vascular congestion. A vasoformative anomaly was present in the submucosa with involvement of the overlying mucosa where the lamina propria was occupied by a dense network of capillary-sized vascular spaces (Figure 1(a)). Immunohistochemistry revealed that the endothelium was positive for vimentin, CD31 (Figure 1(b)), CD34, GLUT-1 (Figure 1(c)), and nonreactive for D2-40 (Figure 1(d)).

\section{Discussion}

This report of a colocolic intussusception with a pathologic lead point (PLP) of an IH in the absence of any cutaneous vascular lesions documents a unique clinical event. The vast majority, 85-90\%, of intussusceptions presenting in infancy are located in the ileocolic region and are regarded as idiopathic in the absence of PLP in $90 \%$ of cases which reflects our own experience in those children requiring intestinal resection. Colocolic intussusception as in our case represents only $2 \%-3 \%$ of all cases. The only other case comparable to our own presented in an almost 3-year-old boy who was intermittently symptomatic with abdominal pain, diarrhea, and eventual hematochezia and was found to have an ileocecal intussusception with a submucosal tumor measuring $2.5 \mathrm{~cm}$ in the cecum; immunohistochemical staining for GLUT-1, the sine qua non for establishing the diagnosis of $\mathrm{IH}$, was not reported in this case, but the histologic features as illustrated and described could represent an IH. The mucosal and submucosal location of the IH in our case is similar in most respects to the cecal lesion in the prior case, but our patient was younger, and the IH was located in the descending colon.

Pathologic lead point in intussusception occurs far less commonly in children, based on individual case studies and case series, than in adults where it has been reported in as high as $90 \%$ of cases $[6,14-19]$. A review of five pediatric series revealed that a PLP was found in less than $10 \%$ of cases (Table 1). The most common PLP in children is the Meckel's diverticulum accounting for $46 \%$ of cases. Polyps of one type or another were present in $13 \%$ of cases. In those studies specifying "multiple polyps," there were examples of Peutz-Jeghers (PJ) polyps in the small intestine $[6,17,18]$; intussusception is reported in approximately $50 \%-70 \%$ of all cases of PJ syndrome [20]. Some have found that PLPassociated intussusceptions occur more commonly in "older children," which is generally regarded as a child at or over 3 years of age. Literature suggests $90 \%$ of all intussusceptions in childhood present before the age of 3 years. The five studies cited in Table 1 are in general agreement that PLP-associated intussusceptions are diagnosed in children over 3 years of age and where Meckel's diverticulum is the most common PLP [6,15-18].

Vascular anomalies including vascular malformations and hemangiomas, as well as other types of benign tumors, are well documented as causes of intussusception in children. Blue rubber bleb syndrome is one of several syndromes with multifocal vascular malformations throughout the intestinal tract. The liver is the most common visceral site of $\mathrm{IH}$, and it is often accompanied by multiple cutaneous IHs; the tumors in the liver are immunoreactive for GLUT-1. Multifocal hemangiomatosis with intestinal involvement is quite rare, but our case is unique with the colon as the only site of IH and as the PLP.

\section{Disclosure}

The authors have no conflicts of interest to declare, and no funding was use for this work.

\section{Conflicts of Interest}

The authors declare that they have no conflicts of interest.

\section{References}

[1] J. Jiang, B. Jiang, U. Parashar, T. Nguyen, J. Bines, and M. M. Patel, "Childhood intussusception: a literature review," PLoS One, vol. 8, no. 7, Article ID e68482, 2013.

[2] E. A. Edwards, N. Pigg, J. Courtier, M. A. Zapala, J. D. MacKenzie, and A. S. Phelps, "Intussusception: past, present and future," Pediatric Radiology, vol. 47, no. 9, pp. 1101-1108, 2017.

[3] C. J. F. Smith, S. F. Friedlander, M. Guma, A. Kavanaugh, and C. D. Chambers, "Infantile hemangiomas: an updated review on risk factors, pathogenesis, and treatment," Birth Defects Research, vol. 109, no. 11, pp. 809-815, 2017.

[4] C. Leaute-Labreze, J. I. Harper, and P. H. Hoeger, "Infantile haemangioma," The Lancet, vol. 390, no. 10089, pp. 85-94, 2017.

[5] N. Apelt, N. Featherstone, and S. Giuliani, "Laparoscopic treatment of intussusception in children: a systematic review," Journal of Pediatric Surgery, vol. 48, no. 8, pp. 1789-1793, 2013.

[6] X. K. Lin, Q. Z. Xia, X. Z. Huang, Y. J. Han, G. R. He, and $\mathrm{N}$. Zheng, "Clinical characteristics of intussusception secondary to pathologic lead points in children: a single-center experience with 65 cases," Pediatric Surgery International, vol. 33, no. 7, pp. 793-797, 2017.

[7] K. R. Anderson, J. J. Schoch, C. M. Lohse, J. L. Hand, D. M. Davis, and M. M. Tollefson, "Increasing incidence of infantile hemangiomas ( $\mathrm{IH})$ over the past 35 years: correlation with decreasing gestational age at birth and birth weight," Journal of the American Academy of Dermatology, vol. 74, no. 1, pp. 120-126, 2016.

[8] M. K. Hunjan, J. J. Schoch, K. R. Anderson et al., "Prenatal risk factors for infantile hemangioma development," Journal of Investigative Dermatology, vol. 137, no. 4, pp. 954-957, 2017.

[9] K. M. Nord, J. Kandel, J. H. Lefkowitch et al., "Multiple cutaneous infantile hemangiomas associated with hepatic angiosarcoma:case report and review of the literature," $\mathrm{Pe}$ diatrics, vol. 118, no. 3, pp. e907-e913, 2006.

[10] E. R. Christison-Lagay, P. E. Burrows, A. Alomari et al., "Hepatic hemangiomas: subtype classification and development of a clinical practice algorithm and registry," Journal of Pediatric Surgery, vol. 42, no. 1, pp. 62-67, 2007.

[11] A. Maruani, M. Piram, D. Sirinelli et al., "Visceral and mucosal involvement in neonatal haemangiomatosis," Journal of 
the European Academy of Dermatology and Venereology, vol. 26, no. 10, pp. 1285-1290, 2012.

[12] K. Utsumi, N. Ogasawara, M. Sasaki et al., "Intussusception in a child caused by capillary hemangioma of the colon," Clinical Journal of Gastroenterology, vol. 3, no. 2, pp. 83-87, 2010.

[13] L. Huang, H. Nakayama, M. Klagsbrun, J. B. Mulliken, and J. Bischoff, "Glucose transporter 1-positive endothelial cells in infantile hemangioma exhibit features of facultative stem cells," Stem Cells, vol. 33, no. 1, pp. 133-145, 2015.

[14] S. Shenoy, "Adult intussusception: a case series and review," World Journal of Gastrointestinal Endoscopy, vol. 9, no. 5, pp. 220-227, 2017.

[15] P. Banapour, R. M. Sydorak, and D. Shaul, "Surgical approach to intussusception in older children: influence of lead points," Journal of Pediatric Surgery, vol. 50, no. 4, pp. 647-650, 2015.

[16] J. C. Rubinstein, L. Liu, M. G. Caty, and E. R. ChristisonLagay, "Pathologic leadpoint is uncommon in ileo-colic intussusception regardless of age," Journal of Pediatric Surgery, vol. 50, no. 10, pp. 1665-1667, 2015.

[17] N. T. Ong and S. W. Beasley, "The leadpoint in intussusception," Journal of Pediatric Surgery, vol. 25, no. 6, pp. 640-643, 1990.

[18] C. W. Wong, S. Jin, J. Chen, P. K. Tam, and K. K. Wong, "Predictors for bowel resection and the presence of a pathological lead point for operated childhood intussusception: a multi-center study," Journal of Pediatric Surgery, vol. 51, no. 12, pp. 1998-2000, 2016.

[19] P. Marsicovetere, S. J. Ivatury, B. White, and S. D. Holubar, "Intestinal intussusception: etiology, diagnosis, and treatment," Clinics in Colon and Rectal Surgery, vol. 30, no. 1, pp. 30-39, 2017.

[20] H. Wang, T. Luo, W. Q. Liu, Y. Huang, X. T. Wu, and $\mathrm{X}$. J. Wang, "Clinical presentations and surgical approach of acute intussusception caused by Peutz-Jeghers syndrome in adults," Journal of Gastrointestinal Surgery, vol. 15, no. 12, pp. 2218-2225, 2011. 


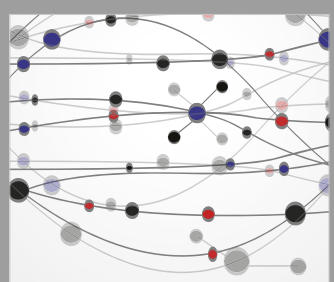

The Scientific World Journal
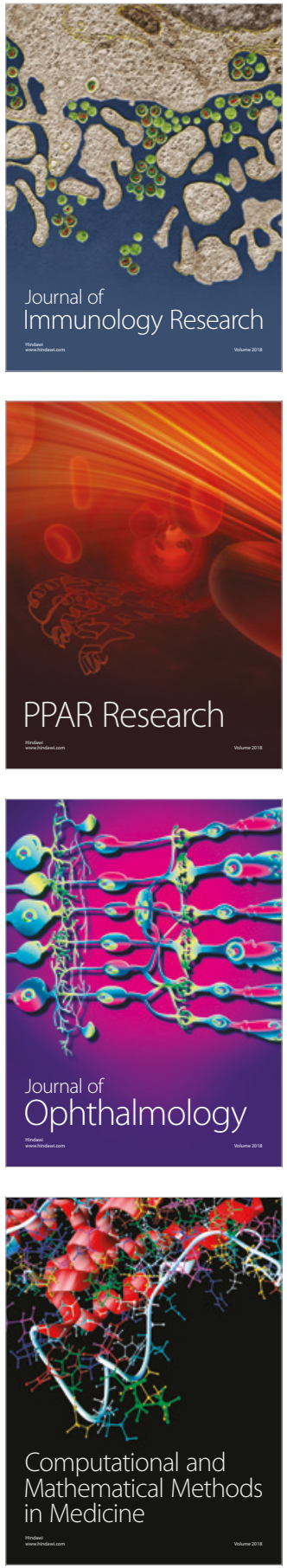

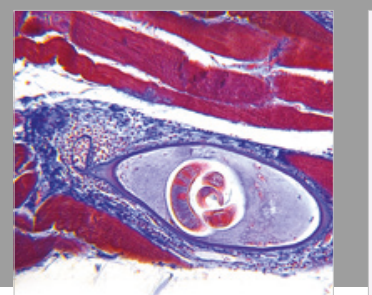

Gastroenterology Research and Practice

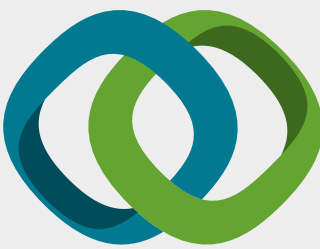

\section{Hindawi}

Submit your manuscripts at

www.hindawi.com
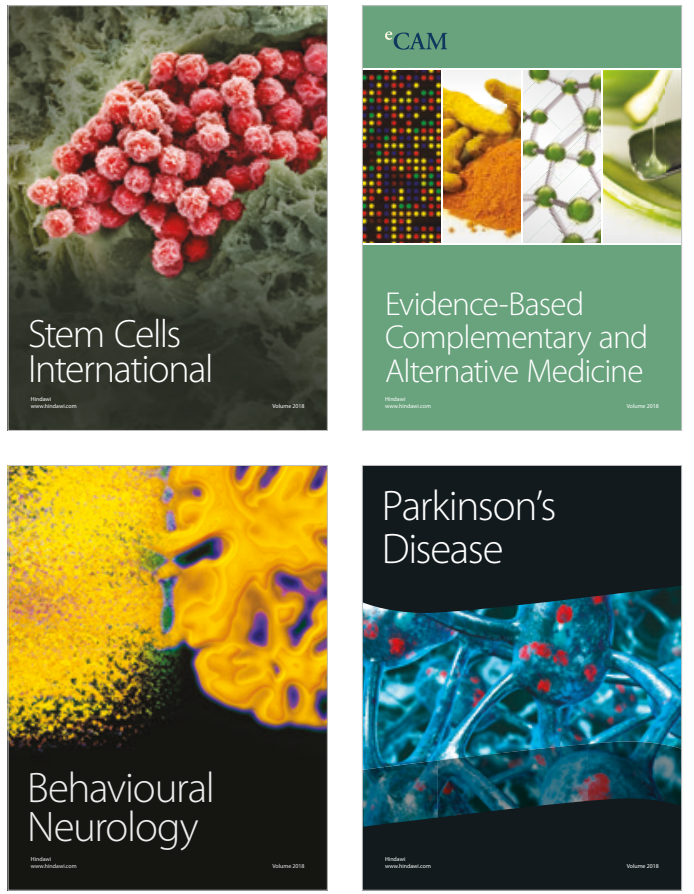

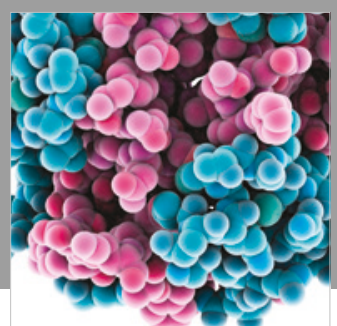

ournal of

Diabetes Research

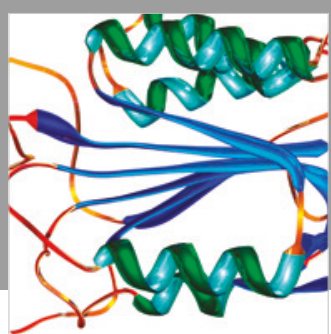

Disease Markers
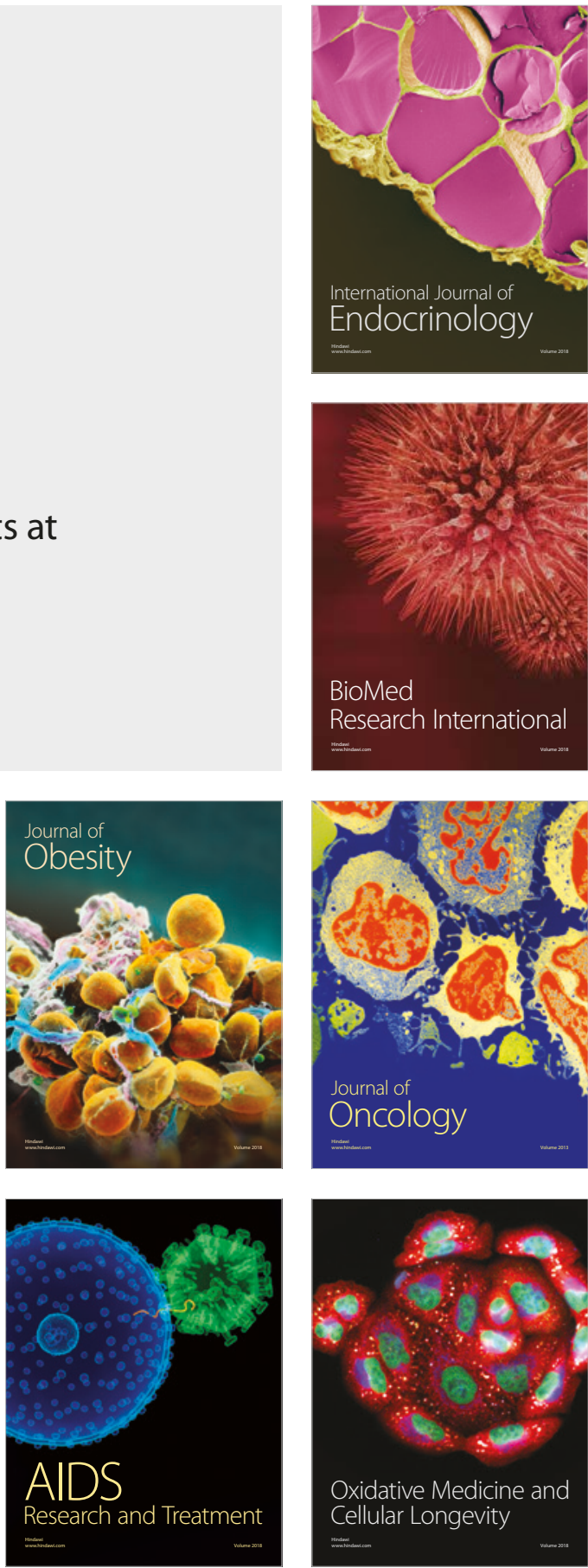